\title{
Effectiveness of Narrative Persuasion on Facebook: Change of Attitude and Intention Towards HPV
}

\author{
Prof. Ubaldo Cuesta \\ Endowed Chair, Division of Health Communication, Complutense University of Madrid, School of Communication
}

Luz Martínez, Ph.D

Division of Health Communication, Complutense University of Madrid, School of Communication

Victoria Cuesta Ph.D. Cand

., Division of Health Communication, Complutense University of Madrid, School of Communication

\begin{abstract}
Information, detection and prevention are very important factors in sexually transmitted diseases such as human papillomavirus, which is linked to cervical cancer and other cancers (WHO, 2015). This paper aims to demonstrate empirically whether the use of narrative in new media, such as Facebook, produces a greater impact on attitudes and intention in sex education issues, such as human papillomavirus, than the same information presented in non-narrative. Also, the role of the viewer's involvement in this persuasive effect is analysed. A group of young university students was tested before and after viewing a Facebook profile on HPV in a narrative vs non-narrative format. The narrative proved to be more effective than the non-narrative, provoking a more positive attitude towards periodic medical check-ups and towards the intention of being tested for HPV. Additionally, narrative transportation proved to have a direct effect on attitude, while involvement with both the story and the character play a moderating role on intention. In conclusion, this paper demonstrates that structured narrative format in Facebook is an effective tool in the field of health education and prevention of $\mathrm{HPV}$, which could also play a role in preventing cervical cancer.
\end{abstract}

Keywords: Effectiveness of Narrative Persuasion on Facebook Change of Attitude and Intention Towards HPV

\section{Introduction}

Human papillomavirus (HPV) is the most common sexually transmitted disease in the world. As the World Health Organization (WHO, 2015) indicates, most sexually active women and men will contract the infection at some point in their lives. There are many types of HPV and the infection usually goes away without any intervention, but certain types of HPV can persist and cause cancer. This is important because more than $70 \%$ of cervical cancers contain human papillomavirus (Types 16 and 18). In 2012, the World Health Organization estimated that about 500,000 women are infected every year and that this cancer resulted in 270,000 deaths. The use of preventive measures (i.e. condom) is recommended for prevention, although it is only effective in $60-70 \%$ of the cases, since the virus can be transmitted by contact of genital areas that are not covered. In recent years, certain groups have reported alleged cases of side effects of the vaccine. Today, a continuous social debate has led countries like the US and Japan to withdraw the vaccine from immunization schedules, while in other countries as Mexico the government has launched public awareness campaigns targeting parents to vaccinate their children. This situation is reflected on the Internet in the form of comments, testimonies and various antivaccination movements.

A very important aspect of sexually transmitted diseases is awareness of the existence of the disease, its transmission and methods of prevention. The study by Stephens and Tomas (2014) evidences that most of the young women reported knowing about the vaccine knew little about the disease itself. Evers et al. (2013), in their research of the social network as a tool for sex education among young people, found that most people seek information after being infected and that there 
is a great misinformation around the disease, thereby causing prejudice and stigmatization (Evers, Albury, Byron and Crawford, 2013).

For all these reasons, it is essential to utilize effective strategies for the promotion of sexual health, while providing relevant information on HPV presented in an attractive way and using all available tools to help the public to understand, normalize and prevent future HPV-related cancers.

\section{The Power of Narrative and Communication for Health}

Throughout history, mankind has used different narratives to share information, change beliefs and inspire behaviours (Green and Brock, 2005). Through them, people experience emotional reactions similar to those experienced in everyday life in first person (Tan, 1996). Narratives have a great persuasive potential by involving the viewer in a story while offering information and behavioural patterns that an individual acquires vicariously or through modelling (Hackett and Lent, 1992; Bandura, 1995). According to Cognitive Social Theory (Bandura and Walters, 1977), the individual also learns by observing models, acquiring knowledge and skills without having to depend only on expensive direct experience. By observing a subject being rewarded for his behaviour the observers' behaviour is also reinforced; therefore, through observation of the models represented in a narrative, knowledge, values, cognitive abilities and new styles of behaviour are transmitted (Bandura, 2004; Schunk and Zimmerman, 1997). Narrative persuasion researches have shown that a message can be more persuasive if presented in narrative form rather than explicitly announced (Slater and Rouner, 2002; Moyer-Guse and Nabi, 2010; Oliver, Dillard, Bae and Tamul, 2012). The narrative, in addition to a structure, presents information about scenes, characters or unresolved conflicts and offers resolutions that serve as models (Bandura, 2004; Hackett and Lent, 1992). These researches show the effectiveness of storytelling for the transmission of knowledge, the acquisition of new values and the change of behaviour (Murphy, Frank, Moran and Patnoe, 2011; Niederdeppe, Shapiro and Porticella, 2011).

In the present research, we analyse the persuasive effectiveness of a narrative format versus a non-narrative format on a Facebook profile related to HPV content.

In order to study this persuasive effect, an experimental study has been carried out, presenting the same information but in two different ways: one Facebook profile containing information presented in a narrative format (by introducing a personal story of a patient who suffers HPV), and another identical version but in a non-narrative format.

\section{Involvement of the viewer}

According to the Extended Elaboration Probability Model (E-ELM) proposed by Slater and Rouner (2002), the persuasive capacity of the narrative is related to its ability to engage or involve the viewer. Green and Brock (2000) believe that someone who is involved will not reflect deeply on the implicit arguments, thereby facilitating the persuasive impact. Therefore, the degree which viewers are emotionally involved to, with a story and its characters, has an impact on the processing and effects of the message (Moyer-Gusé, Chung and Jain, 2011; Tal-Or and Cohen, 2010). Implication in narrative, reflects pre-existing beliefs, attitudes, and values, and makes us care about a topic and process the message more intensely (Sherif, Sherif and Nebergall, 1965). It is also defined as the degree of concern for the story and its characters, the way in which it develops and what it means (Slater and Rouner, 2002). When people are "involved," they focus on the message and react emotionally, pay attention to it, get caught up in the action and identify with the character (Bryant and Comisky, 1978). Other research has examined the involvement of the audience as parasocial interaction (PSI), a perceived friendship between a member of the audience and the character (Horton and Wohl, 1956). So, we can define the involvement of the viewer as an affective, cognitive and behavioural participation produced during the exposure to a message (Rubin and Perse, 1987).

\subsubsection{Implication with the story}

Narrative transportation, or transportation, also defined as commitment, immersion or absorption by a narrative (Bandura, 2004; Gerrig, 1993; Slater and Rouner, 2002), refers to the interest by which the spectators follow the events presented in the story (Green and Block, 2000). When transportation occurs, acceptance of the message increases without thorough reflection. Related to its persuasive effects, transportation increases the perception of realism (Green, Brock and Kaufman, 2004), helps with character identification (Green, 2006) and modulates factors such as perceived self-efficacy and feelings of vulnerability (Moyer-Gusé and Lather, 2011; Murphy, Frank, Chatterjee and Baezconde-Garbanati, 2013).

\subsubsection{Involvement with the character}


Involvement with the character increases attention span, serves as a mental rehearsal and models behaviour (Sharf, Freimuth, Greenspon, and Plotnick, 1996; Sood, 2002). Some authors define it as the spectator assuming the role of a character and substituting their identity as an audience member with that of the character (Cohen, 2001). Staler and Rouner (2002) define it as the process by which an individual perceives the character's similarities to him, or considers the character as someone to have a social relationship with. For our research, we refer to the work made by Moyer-Gusé (Moyer-Gusé 2008; Moyer-Gusé et al., 2011) that considers identification, wishful identification, perceived similarity, parasocial interaction and liking as essential components of the viewer's involvement with a character.

Identification with the character: the spectator experiences what happens to the character by vicariously participating in events in the narrative and replacing his own personal identity with the character's (Cohen, 2001, 2006). The character becomes a model that allows the viewer to imagine himself in the same situation (Bandura, 1986), which increases the likelihood that the viewer will accept the beliefs and attitudes implied in the narrative (Tal-Or and Cohen, 2010; Murphy et al., 2013; Moyer-Gusé, 2008; Graaf, Hoeken, Sanders and Beentjes, 2012). Works such as Suruchi Sood (2002) on the consumption of a radio series called Tinka Tinka Sunk, which deals with issues such as the situation of women in India, dowry, family and community, show that when the audience identifies with the characters and the story, they are involved and evaluate the series in terms of their own lives, provoking reflection on the themes and changes in behaviour.

Wishful identification: the viewer admires the character and wants to be or act like him (Giles, 2002; Hoffner and Buchanan, 2005). Researches have shown that audience members change their appearance, attitudes, values and behaviour to resemble celebrities they admire (Boone and Lomore, 2001; Basil, 1996). Cognitive Social Theory states that viewers want to emulate attractive and successful models (Bandura, 1986). Hoffner and Buchanan (2005), in their research on the wishful identification, found that attributes such as intelligence, success, attractiveness, respect and popularity play an important role in the formation of impressions, finding that both men and women feel a greater identification of wishful towards characters perceived as successful and admired by others.

Perceived similarity: It is a cognitive evaluation of what one has in common with the character (Cohen, 2001). This degree of similarity can occur in relation to physical attributes, demographic variables, situations or personality traits (Eyal and Rubin, 2003; Turner, 1993). Similarity enhances the likelihood of a model being imitated (Bandura, 2004; Hoffner and Buchanan, 2005) and its values and beliefs will be taken into account (Moyer-Gusé, 2008).

Parasocial Interaction (PSI): It was initially described as the apparent "face-to-face" relationship between the spectator and the interpreter during a media situation (Horton and Wohl, 1956), although later researches use it to refer to an affective bond which persists outside the context of media use (Giles, 2002). This interaction has similar characteristics to a traditional interpersonal relationship, with the exception of reciprocity, which makes the viewers to perceive a character as part of their social life and affects their emotions and behaviours (Hoffner and Tian, 2010; Rubin, Perse and Powell, 1985). In two studies about PSI and its relationship to loneliness or grief in a forced break between the spectator and a character due to a writers' strike; or the disappearance of the character, it has been verified that these breaks can be compared with those in real-life relationships (Eyal and Cohen, 2006; Moyer-Gusé and Lather, 2011). PSI has also been shown to influence engagement and identification with the characters (Nabi and Kremar, 2004), which facilitates the acceptance of stigmatized groups through parasocial contact (Schiappa, Gregg, and Hewes, 2005) and increases satisfaction with the media (Hartmann and Goldhoorn, 2011).

Liking: It refers to a positive evaluation of the character and reflects an affective, cognitive and behavioural reaction (Cohen, 2001; Giles, 2002; Hoffner and Cantor, 1991, Nabi and Kremar, 2004). Although, as Eagly and Chaiken (1993) indicate, this assessment can also be negative, manifesting as disapproval or rejection. Usually, we are attracted to admirable or socially successful characters, and by those we share values, experiences or attitudes with (Bandura, 2001). We like characters whose actions and motivations we judge as appropriate (Hoffner and Cantor, 1991), although if we like a character we are able to provide a moral justification for their inappropriateness (Krakowiak and Tsay-Vogel, 2013). Researches show that liking makes the viewpoints, attitudes and actions of the characters better valued and taken into account (Hoffner and Tian, 2010; Moyer-Gusé et al., 2011).

\section{Narrative in digital media}

The development of the Internet has led to the emergence of diverse platforms that enhance the participation and interaction of users, such as social networks. These are virtual communities that provide information, connect people and present new ways of communication and expression (Salamanca, 2004). Studies on mediation and narrative in social networks show that they are new foundations on which to build or show stories (De Fina and Georgakopoulou, 2015; Shlezak, 2015; Jong, 
2015). These new forms of narrative or storytelling are being analysed by communication researchers for the promotion of healthier behaviours in relation to gender, sexual health and weight control (Russo and Illanes, 2013; Merchant et al., 2014; Gold et al., 2012). These stories work through words, images and sounds, regardless of the interface (Barhtes, 1991; Page, 2010) and are tools for spreading knowledge, culture and points of view (Tolisano, 2009). They appeal to emotions, persuade and change opinion (Salmon, 2008). They also serve to transmit knowledge and experiences and help people to relate with each other.

Due to its popularity, its ability to distribute different strategies and its ability to adapt content, Facebook has a great potential for promoting health-related behavioural changes (Merchant et al., 2014; Ballantine and Stephenson, 2011; Valle, Tate, Mayer, Allicock and Cai, 2013; Langley, Wijn, Epskamp and Van Bork, 2015). Through these stories on Facebook we can connect with other people and connect these people with our own experiences. Research (Gold et al. 2012) has shown the persuasive effect of narrative on Facebook for the promotion of sex education by presenting information through characters that take shape in a Facebook profile. These narratives can result in acquired knowledge, personal reflection and shared patterns of behaviour and beliefs (Salmon, 2008).

\section{Method}

\section{Objectives, Hypotheses and Research Questions}

The objective of this study was to analyse if the exposure to a narrative about HPV on a Facebook profile provokes a greater effect than an identical profile presented in a non-narrative format.

We analysed the effect to this exposure by measuring the change in attitude towards medical check-ups as well as the intention of being tested for HPV.

The roles of the following variables were also investigated: 1) involvement of the spectator with the narrative (transportation), 2) identification, 3) similarity 4) wishful identification 5) PSI and 6) liking.

The following hypotheses and research questions $(\mathrm{RQ})$ were proposed:

HP1: Exposure to HPV narrative content on a Facebook profile will cause greater effects on the attitude towards the importance of periodical medical check-ups than a non-narrative profile.

HP2: Exposure to HPV narrative content on a Facebook profile will cause greater effects on the intent to get tested for HPV than a non-narrative profile.

RQ1: What is the Role of Transportation, Identification, Similarity, Wishful identification, PSI and Liking in Attitude Toward Periodical Medical Check-ups?

RQ2: What is the Role of Transportation, Identification, Similarity, Wishful identification, PSI, and Liking in intention toward HPV testing?

\section{Procedures and Sample}

One hundred and fourteen student volunteers from Complutense University of Madrid: 18 to 23 years old $(\square=19.18, S D=$ 1.46), $75 \%$ female and $25 \%$ male.

An inter-subject one-factor design was used. The independent variable was defined as "format type", presenting two levels: narrative format (through the experience of a "real person") versus non-narrative (presented in an institutional style).

In the narrative format, information was presented through videos and stories narrated by a female university student very similar to the participants, whereas in the non-narrative format it was presented in videos or images without real people. In both cases it was verified that the information was identical in content ${ }^{1}$.

The sample was randomly divided into two groups: one was assigned to be presented with the content in a narrative format and the other one (control group) in a non-narrative manner. The control group (non-narrative format) was informed that it 
was written by an institutional Facebook administer, while the experimental group (narrative format) was told that it was written by a young girl.

Both groups were exposed to a standardized browsing projection of the Facebook profiles by one of our research members. Each group observed their assigned profile for ten minutes and under identical conditions (e.g. number of clicks, browsing pathways, time spent on each post).

Prior to exposure, participants completed a pre-test questionnaire about their knowledge of HPV, their attitude towards screening and behaviour towards HPV testing. After viewing the Facebook profile, the subjects completed a post-test questionnaire collecting their reactions to the profile, knowledge, attitude and intention related to HPV testing.

All the subjects were thoroughly debriefed at the end of the session.

\section{Stimulus}

Two Facebook profiles were created offering the same information about HPV: its relationship to cervical cancer, general information about medical check-ups and prevention, and beliefs or prejudices related to talking about HPV or having HPV. Both profiles consisted of the same number and types of publications (videos, images, links to specialized sources and informative posters). In the narrative profile, the story of a real person was presented: a girl who has been recently diagnosed with HPV and is waiting for the test results to find out the type she has. She posts to her profile, telling her story with publications and videos explaining what HPV is and providing information about testing, prevention and diagnosis. She talks about her conversations with her family, friends and partner about prejudices, the importance of the vaccination and what to do if you have been diagnosed with it. The non-narrative format profile is portrayed on a formal-institutional tone, providing the same number of videos and the same publications, with more impersonal language in all posts. In order to accomplish this, new videos were created to replace those presented by the aforementioned female character in the narrative profile but containing the same information and lasting the same amount of time.

\section{Measures}

\section{Attitude.}

We used a 7-point Likert scale adapted from others (Murphy et al., 2011). The questions measure young people's perception of the importance of routine medical check-ups, having HPV support, feelings of embarrassment or shame about having HPV, and asking their partner to get tested. Example of items presented included: "It is important for me to have periodic HPV screenings". It was evaluated in both the pre-test (Cronbach's alpha= .67) and the post-test (Cronbach's alpha $=.78)$.

\section{Intention.}

Pre- and post-test were evaluated using a 7-point Likert scale adapted from others (Murphy et al., 2011; Moyer-Gusé et al., 2011) and measured behaviours as talking about HPV or HPV testing with items such as: "Currently, I'm likely to get tested for HPV'. (Cronbach's alpha pre-test= .80; Cronbach's alpha post-test $=.72$ )

\section{Transportation.}

Post-test was measured using an adaptation of the Green and Brock scale (2000), from which 6 items were used on a 7point Likert scale. The statements were adapted according to the type of profile. Some examples of the items used include: "I was mentally involved in the story" (narrative format)/ "I was mentally involved in the information" (non-narrative format). (Cronbach's alpha= .84)

\section{Identification.}

Six items from the identification scale proposed by Cohen (2001) on a 5-point Likert scale were used. Examples: "I could understand the events of the program similarly to how Maria understood them" (narrative)/ "I could understand the events of the program similarly to how the institution understood them." (non-narrative). (Cronbach's alpha= .78)

\section{Wishful identification.}

Four items from the Hoffner and Buchanan (2005) adaptation of Hoffner's (1996) wishful identification scale were used, also on a 5-point Likert scale. Example: "María is the type of person I would like to be" (narrative); "The institution represents the kind of person I would like to be" (non-narrative). (Cronbach's alpha= .89)

\section{Similarity.}


Seven items from the similarity scale of McCroskey, Richmond and Daly (1975) were used, on a 7-point Likert scale. Example: "María thinks like I do" (narrative); "The position of the institution is the same as I think" (non-narrative). (Cronbach Alpha= .81)

Parasocial interaction (PSI).

An adaptation of the PSI scale of Rubin and Perse (1987) and its adaptation by Sood (2002) was used. It consisted of 6 items on a 5-point Likert scale. Example: "When María shows how she feels about something, she helps me to form my own opinion on that subject" (narrative); "When the institution shows something, it helps me to form my own opinion on that subject" (non-narrative). (Cronbach's alpha $=.75$ )

\section{Liking.}

We used a 5-point Likert scale adapted from other researches (Zillmann and Bryant, 1975; Krakowiak and Tsay-Vogel, 2013; Hoffner and Buchanan, 2005), with a total of 6 items such as: "Maria seems attractive" (narrative)/ "The institution seems attractive." (non-narrative). (Cronbach Alpha $=.80$ )

\section{Analysis and results}

\section{Effects of narrative type on attitude and behaviour}

Hypothesis 1 was confirmed: exposure to a narrative format causes greater effects on the attitude towards the importance of routine medical check-ups than exposure to a non-narrative profile. The Wilcoxon test showed that the attitude towards the importance of HPV check-ups in the narrative profile significantly increased between the assessments made before ( $\square=$ $3.90)$ and after ( $(=5.36)$ the exposure to the stimulus $(p<0.05)$, while in the non-narrative profile this change was lower (from $\square=4.07$ to $\square=4.78$ ).

Hypothesis 2 was also confirmed: exposure to a narrative format causes greater effects on the intention to get tested for HPV than a non-narrative profile. The Wilcoxon test showed that intention increased from 3.60 to $5.02(p<0.05)$. In the non-narrative profile the change was also lower (from $\square=3.13$ to $\square=4.01$ ).

The role of transportation, identification, similarity, wishful identification, PSI and liking

The research questions proposed in our study investigate the impact of 1) transportation, (2) identification, (3) similarity, (4) Wishful identification, (5) PSI and (6) liking on attitude towards medical check-ups. The role these variables may play on the intention to get tested for HPV was also analysed.

An analysis of bivariate correlations for each of the variables was performed.

The data in table 1 shows a significant positive correlation $(p<.05)$ between transportation and attitude towards check-ups $(r=0.330 ; p=.033)$. The variable identification shows a significant but less dramatic relationship $(r=0.252, p=.10)$. On Table 2, effects of these variables (Transportation, Identification, Similarity, Wishful identification, PSI and Liking) on intention of being tested show a significant correlation of transportation, identification and PSI.

\section{Discussion}

\section{The importance of the narrative format}

The way in which narrative influences in attitude and behaviour of viewers have been analysed by many researchers; however, most of the works have been based on traditional media: television, film and radio (Moyer-Gusé, 2008; Sood, 2002). The aim of this study was to examine the efficacy of narrative in new media, such as social networks. It also aimed to investigate the effect of narrative vs. non-narrative information on a Facebook profile. Additionally, the role of the viewer's involvement with the story and with the character was analysed.

Our study revealed the greater effectiveness of using a narrative format in these new digital platforms.

Although both profiles provoked an increase in levels of attitude and intention, participants who received the information in a narrative format showed a significantly greater change, both in their attitude towards routine medical check-ups and in their intention to get tested for HPV. These data relate to other studies where narrative vs. non-narrative format has demonstrated to persuade more effectively in conventional media (Murphy et al., 2013; Niederdeppe et al., 2011; Oliver et al., 2012; Moyer-Gusé and Nabi, 2010).

The consequences of our results are very relevant, since they seem to indicate the importance of creating narrative format in social media. For example, these types of Facebook profiles could be created by official institutions. It is a question of 
allowing digital media users themselves to generate processes of mutual persuasion. These procedures imply empowering certain individuals to act as social mediators in health promotion programs. Moreover, this proposal aligns well with current social movements of citizen's shared responsibilities in their health care.

\section{Understanding the power of narrative}

Researches in the field of narrative persuasion attempts to determine a theoretical framework for understanding the intrinsic mechanisms of the power of narrative (Tal-Or and Cohen, 2010; Green, Strange and Brock, 2002; Dahlstrom, 2012). The results of our study confirm that transportation and identification are related to attitude change towards medical check-ups, on a social media platform such as Facebook.

Our data also confirm that it is necessary to produce transportation and identification to provoke behavioural changes, but it is also necessary-to establish PSI. In other words, in order for the intention to change, the PSI variable acquires special relevance.

Future researches should explore this result, but a reasonable explanation might be as follows: PSI is conceptually very closely related to behavioural execution, as is defined as the imaginary interaction with the character. This symbolic interaction would mobilize the intention to change behaviour.

If this hypothesis is verified, the practical consequences are very relevant. They would indicate the importance of using narratives and models that favour PSI. As we have seen, this situation will only occur if is possible to provoke transportation and identification with a character. In this sense, it would be necessary to get the active participation of the young people in the health promotion campaigns. It is a question of empowering people themselves to control their own health, in line with recent proposals for social co-responsibility and health.

\section{Study limitations and future research directions}

This paper presents some limitations to be considered in future researches. In the first place, it would be advisable to use a larger and more diversified sample in order to obtain broader conclusions about the new digital narrative and their effect of HPV prevention campaigns. Secondly, because of the nature of Facebook, it would be useful to stimulate the subjects over a longer period of time to analyse the effects of long term exposition. It would have also been interesting to conduct an analysis of users' behaviour towards HPV testing or check-ups after a period of time, which would show if that change in behavioural intent becomes a real behavioural change. Finally, the importance of the PSI variable should be analysed in depth and test if the advanced hypothesis in this study is confirmed.

\section{References}

[1] Ballantine, P. W. and Stephenson, R. J. (2011). Help me, I'm fat! Social support in online weight loss networks. Journal of Consumer Behaviour, 10(6), 332-337.

[2] Bandura, A. (1986). The explanatory and predictive scope of self-efficacy theory. Journal of social and clinical psychology, 4(3), 359-373.

[3] Bandura, A., (1995) Self-efficacy in changing societies, Cambridge university press.

[4] Bandura, A. (2004). Health promotion by social cognitive means. Health education \& behavior, 31(2), 143-164.

[5] Bandura, A. and Walters, R. H. (1977). Social learning theory.

[6] Barthes, R., (1991). Análisis estructural del relato, Premia: México, D.F

[7] Basil, M. D. (1996). Identification as a mediator of celebrity effects. Journal of Broadcasting \& Electronic Media, 40, 478-495.

[8] Boone, S, D. and Lomore, C. D. (2001) Admirer-celebrity relationship among young adults. Explaining perceptions of celebrity influence on identity. Human Communication Research. 27, 432 - 465.

[9] Bryant, J. and Comisky, P. W. (1978). The effect of positioning a message within differentially cognitively involving portions of a television segment on recall of the message. Human Communication Research, 5(1), 63-75.

[10] Cohen, J. (2001). Defining identification: A theoretical look at the identification of audiences with media characters. Mass Communication \& Society, 4(3), 245-264.

[11] Cohen, J. (2006). Audience identification with media characters. In: Bryant, J., Vorderer, P. (Eds.), Psychology of Entertainment. Lawrence Erlbaum, Mahwah, NJ, pp. 183-198.

[12] Cuesta, U., Peñafiel, C., Terrón, J.L., Bustamante, E. y Gaspar, S. (2017): Comunicación y Salud. Dextra, Madrid.

[13] Dahlstrom, M. F. (2012). The persuasive influence of narrative causality: Psychological mechanism, strength in overcoming resistance, and persistence over time. Media Psychology, 15(3), 303-326.

[14] De Fina, A. and Georgakopoulou, A. (2015). The handbook of narrative analysis. John Wiley \& Sons. 
[15] Eagly, A., H., and Chaiken, S. (1993). The psychology of attitudes. Fort Worth, TX: Harcourt Brace Jovanovich.

[16] Evers, C. W., Albury, K., Byron, P. and Crawford, K. (2013). Young People, Social Media, Social Network Sites and Sexual Health Communication in Australia:" This is Funny, You Should Watch It". International Journal of Communication, 7, 18.

[17] Eyal, K. and Rubin, A. M. (2003). Viewer aggression and homophily, identification, and parasocial relationships with television characters. Journal of Broadcasting \& Electronic Media, 47(1), 77-98.

[18] Gerrig, R. J. (1993). Experiencing narrative worlds: On the psychological activities of reading. Yale University Press.

[19] Giles, D. C., (2002). Parasocial interaction: A review of the literature and a model for future research. Media Psychology, 4, 279 - 305.

[20] Gold, J., Pedrana, A. E., Stoove, M. A., Chang, S., Howard, S., Asselin, J. and Hellard, M. E. (2012). Developing health promotion interventions on social networking sites: recommendations from The FaceSpace Project. Journal of medical Internet research, 14(1), e30.

[21] Graaf, A. G., Hoeken, H., Sanders, J. and Beentjes, J., W., J., (2012). Identification as a Mechanism of Narrative Persuasion, Communication Research, 39, 802 - 823

[22] Green, M. C. and Brock, T. C. (2000). The role of transportation in the persuasiveness of public narratives. Journal of Personality and Social Psychology, 79, 701-721.

[23] Green, M. C. and Brock, T. C. (2005). Persuasiveness of narratives. Persuasion: Psychological insights and perspectives, 2, 117-142.

[24] Green, M. C., Brock, T. D. and Kaufman, G. F. (2004). Understanding media enjoyment: The role of transportation into narrative worlds. Communication Theory, 14, 311-327.

[25] Green, M. C., Strange, J. J., and Brock, T. C. (2002). Narrative impact: Social and cognitive foundations. Mahwah, NJ: Erlbaum.

[26] Green, M. C. (2006). Narratives and cancer communication. Journal of communication, 56(s1), S163-S183.

[27] Hackett, G. and Lent, R. W. (1992). Theoretical advances and current inquiry in career psychology. Handbook of counseling psychology, 2, 419-452.

[28] Hartmann, T. and Goldhoorn, C. (2011). Horton and Wohl Revisited: Exploring Viewers' Experience of Parasocial Interaction, Journal of Communication, 61, 1104-1121.

[29] Hoffner, C. (1996). Children's wishful identification and parasocial interaction with favorite television characters. Journal of Broadcasting \& Electronic Media, 40(3), 389-402.

[30] Hoffner, C. and Buchanan, M. (2005). Young adults' wishful identification with television characters: The role of perceived similarity and character attributes. Media psychology, 7(4), 325-351.

[31] Hoffner, C. and Cantor, J. (1991). Perceiving and responding to mass media characters. In: Bryant, J., Zillmann, D. (Eds.), Responding to the Screen: Reception and Reaction Processes. Erlbaum, Hillsdale, NJ, pp. 63-102

[32] Hoffner, C. and Tian, Q. (2010). Parasocial Interaction With Liked, Neutral, and Disliked Characters on a Popular TV Series, Mass Communication and Society, 13, 250-269.

[33] Horton, D. and Wohl, R. R. (1956). Mass communication and parasocial interaction: Observations on intimacy at a distance. Psychiatry, 19, 215-229.

[34] Jong, A. (2015). Using Facebook as a space for storytelling in geographical research. Geographical Research, 53(2), $211-223$.

[35] Krakowiak, K. M. and Tsay-Vogel, M. (2013). What makes characters' bad behaviors acceptable? The effects of character motivation and outcome on perceptions, character liking, and moral disengagement. Mass Communication and Society, 16(2), 179-199.

[36] Langley, D. J., Wijn, R., Epskamp, S. and Van Bork, R. (2015). Should I Get That Jab? Exploring Influence to Encourage Vaccination via Online Social Media. In ECIS.

[37] McCroskey, J.C, Richmond. V.P. and Daly. J. A. (1975) The development of a measure of perceived homophily in interpersonal communication. Human Communication Research, 2, 323-332.

[38] Merchant, G., Weibel, N., Patrick, K., Fowler, J. H., Norman, G. J., Gupta, A. and Donohue, M. (2014). Click "like" to change your behavior: a mixed methods study of college students' exposure to and engagement with Facebook content designed for weight loss. Journal of medical Internet research, 16(6), e158.

[39] Moyer-Gusé, E. (2008). Toward a theory of entertainment persuasion: explaining the persuasive effects of entertainment-education messages. Communication Theory. Vol. 18, n 3, pp. 407- 425.

[40] Moyer-Gusé, E. and Nabi, R. L. (2010). Explaining the persuasive effects of entertainment-education: An empirical comparison of three theories. Human Communication Research, 36, 26-52.

[41] Moyer-Gusé, E., Chung, A., H. and Jain, P., (2011). Identification with characters and discussion of taboo topic after exposure to an entertainment narrative about sexual health. Journal of communication, 61, 387-406. 
[42] Moyer- Gusé, E. and Lather, J., (2011). How do we react when our favorite characters are taken away? An examination of a temporary parasocial breakup. Mass communication and society, 14, $196-215$.

[43] Murphy, S., T., Frank, L., M., Moran, M, B. and Patnoe-Woodley, P., (2011) Involved, Transported or Emotional? Exploring the Determinants of Change in Knowledge, Attitudes and Behavior in Entertainment Education. Journal of Communication, Vol. 61, issue 3, pages 407-431, June 2011.

[44] Murphy, S. T., Frank, L. B., Chatterjee, J. S. and Baezconde-Garbanati, L. (2013). Narrative versus nonnarrative: The role of identification, transportation, and emotion in reducing health disparities. Journal of Communication, 63(1), 116137.

[45] Nabi, R., L. and Kremar, M., (2004). Conceptualizing media enjoyment as attitude: Implications for mass media effects research. International Communication Association, 4, 288 - 310.

[46] Navarro-Illana, P., Diez-Domingo, J., Navarro-Illana, E., Tuells, J., Alemán, S. and Puig-Barberá, J. (2014). Knowledge and attitudes of Spanish adolescent girls towards human papillomavirus infection: where to intervene to improve vaccination coverage. BMC public health, 14(1), 490.

[47] Niederdeppe, J., Shapiro, M. A. and Porticella, N. (2011). Attributions of responsibility for obesity: Narrative communication reduces reactive counterarguing among liberals. Human Communication Research, 37(3), 295-323.

[48] Oliver, M. B., Dillard, J. P., Bae, K. and Tamul, D. J. (2012). The effect of narrative news format on empathy for stigmatized groups. Journalism \& Mass Communication Quarterly, 89(2), 205-224.

[49] Organización Mundial de la Salud. Human papillomavirus (HPV) and cervical cáncer. Fact sheet $N^{\circ} 380$ September 2013, última revisión marzo de 2015. http://www.who.int/mediacentre/factsheets/fs380/en/

[50] Page, R. (2010). Re-examining narrativity: Small stories in status updates. Text \& Talk-An Interdisciplinary Journal of Language, Discourse \& Communication Studies, 30(4), 423-444.

[51] Rubin, A. M., Perse, E. M. and Powell, R. A. (1985). Loneliness, parasocial interaction, and local television news viewing. Human Communication Research, 12, 155 - 180.

[52] Rubin, A. M. and Perse, E. M. (1987). Audience activity and soap opera involvement, Human Communication Researh, vol. $14, \mathrm{~N} 1 \frac{1}{4}$, Winter, $246-268$.

[53] Russo, A. P. L. H. and Illanes, N. I. (2013). Nuevas narrativas en Comunicación de Salud: El storytelling y la conquista emocional del paciente. Anuario electrónico de estudios en Comunicación Social" Disertaciones", 6(2 Jul-Dic), 47-71.

[54] Schunk, D. H. and Zimmerman, B. J. (1997). Social origins of self-regulatory competence. Educational psychologist, 32(4), 195- Tomás, Revista Hallazgos No. 1, páginas 50-57.

[55] Salmon, C. (2008). "Storytelling. La máquina de fabricar historias y formatear las mentes". Editorial Península. ISBN 9788483078358 (264 págs.).

[56] Schiappa, E., Gregg, P. B. and Hewes, D. E. (2005). The parasocial contact hypothesis. Communication Monographs, 72(1), 92-115.

[57] Sharf, B. F., Freimuth, V. S., Greenspon, P. and Plotnick, C. (1996). Confronting cancer on thirtysomething: Audience response to health content on entertainment television. Journal of Health Communication, 1(2), 157-172.

[58] Sherif, C. W., Sherif, M. and Nebergall, R. E. (1965). Attitude and attitude change: The social judgment-involvement approach. Saunders.

[59] Shlezak, A. (2015). The Narrative Discourse in Facebook Electronic Communication. Procedia-Social and Behavioral Sciences, 209, 476-483.

[60] Slater, M. D. and Rouner, D. (2002). Entertainment-education and elaboration likelihood: Understanding the processing of narrative persuasion. Communication Theory, 12, 173-191.

[61] Sood, S. (2002), Audience involvement and Entertainment-Education, International Communication Association, 12 (2), $153-172$.

[62] Stephens, D. P. and Thomas, T. L. (2014). Social Networks Influence Hispanic College Women's HPV Vaccine Uptake Decision-Making Processes. Women's Reproductive Health, 1(2), 120-137.

[63] Tal-Or, N. and Cohen, J. (2010). Understanding audience involvement: Conceptualizing and manipulating identification and transportation. Poetics, 38(4), 402-418.

[64] Tan, E., S., (1996). Emotion end the structure of narrative film. Film as an emotion machine. Mahwah, NJ. Lawrence Erlaum Associates.

[65] Tolisano, S. R. (2009). How To Guide Digital Storytelling Tools For Educators.

[66] Turner, J. R. (1993). Interpersonal and psychological predictors of parasocial interaction with different television performers. Communication Quarterly, 41, 443 - 43.

[67] Valle C. G., Tate D. F., Mayer D. K., Allicock M. and Cai J. (2013). A randomized trial of a Facebook-based physical activity intervention for young adult cancer survivors. J. Cancer Surviv. 7, 355-368.

[68] Zillmann, D. and Bryant, J. ( 1975 ). Viewer's moral sanction of retribution in the appreciation of dramatic presentations. Journal of Experimental Social Psychology , 11, 572 - 582 .[CrossRef], [Web of Science®] 


\section{Footnotes}

Examples of the same video for the two different Facebook profiles:

https://drive.google.com/open?id=0B7JvnBraOKcYdEIUT2I2M2ITQ0k (narrative format)

https://drive.google.com/open?id=0B7JvnBraOKcYNGRaVEJVUjRYUkk (non-narrative format)

\section{Tables}

Table 1

Spearman correlations between the six variables analysed and the attitude toward check-ups

\begin{tabular}{|c|c|c|c|c|c|c|c|c|}
\hline & & 1 & 2 & 3 & 4 & 5 & 6 & 7 \\
\hline Rho de Spearman & $\begin{array}{l}\text { 1. Attitude } \\
\text { 2. Transportation } \\
\text { 3. Identification } \\
\text { 4. Similarity } \\
\text { 5. Wishful } \\
\text { 6. PSI } \\
\text { 7. Liking }\end{array}$ & $\begin{array}{l}.330^{* *} \\
.252^{*} \\
-.046 \\
.232 \\
.169 \\
.073 \\
\end{array}$ & $\begin{array}{l}672^{*+*} \\
400^{*+*} \\
334^{* *} \\
386^{* *} \\
.281\end{array}$ & $\begin{array}{l}387^{\star \star} \\
472^{* \star \star} \\
509^{* \star *} \\
320^{* *}\end{array}$ & $\begin{array}{l}413^{* * *} \\
540^{* * *} \\
337^{* *}\end{array}$ & $\begin{array}{l}. \\
.654^{*+*} \\
.459^{*+*}\end{array}$ & $.585^{* *+*}$ & \\
\hline
\end{tabular}

* Significant correlation at the level .10 (bilateral)

** Significant correlation at the level .05 (bilateral)

*** Significant correlation at the level .001 (bilateral)

Table 2

Spearman correlations between the seven variables analysed and the intention of being tested for HPV

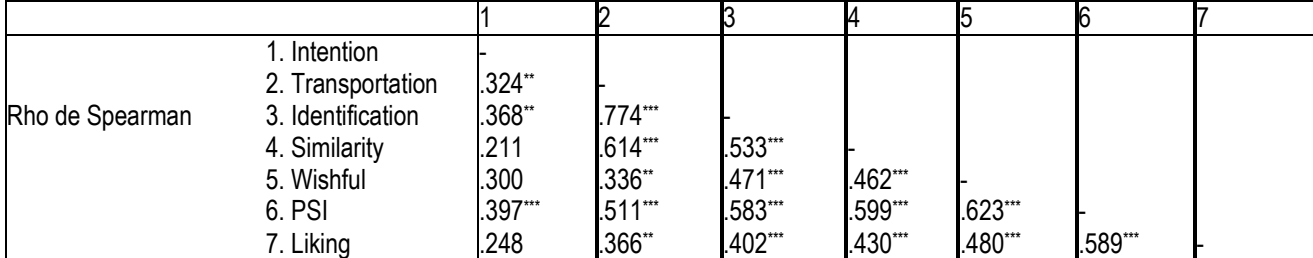

* Significant correlation at the level .10 (bilateral)

** Significant correlation at the level .05 (bilateral)

*** Significant correlation at the level .001 (bilateral) 